Sri Lanka Journal of Urology, 2009, 10, 18-21

Original Article

\title{
Retrocaval ureter: a venous anomaly causing ureteric obstruction
}

\author{
B. Sathesan, A. P. I. Prabath and S. A. S. Goonewardena \\ Department of Urology, National Hospital of Sri Lanka, Colombo, Sri Lanka.
}

\begin{abstract}
Introduction The aim of this study is to report the experience in managing a rare entity, retrocaval ureter.

Patients and methods This is a retrospective study performed in a single urology unit of a tertiary referral center over a period of 8 years since October 2001. The diagnosis of retrocaval ureter was confirmed by retrograde ureteropyelogram. Symptomatic patients underwent open surgical pyelopyelostomy (ureteroureterostomy) after the ureter had been transposed to its normal anatomic position. Post surgical relief of ureteric obstruction was confirmed by ${ }^{99 \mathrm{~m}}$ Tc DTPA renogram.
\end{abstract}

Results There were 5 patients with retrocaval ureter. Mean age of the patients was 33 years (range 27-39 years). Out of 5 patients 4 were males. All 5 patients were presented with right flank pain and 3 of them had haematuria and a small mobile renal stone. All patients had type 1 right-sided retrocaval ureter. Associated anomalies were seen in none of the patients. All patients were asymptomatic after the surgical correction. Post operative ${ }^{99 \mathrm{~m}}$ Tc DTPA renograms were normal in all patients.

Conclusion Retrocaval ureter though rare can easily be diagnosed. Open surgical correction gives good results.

Retrocaval (circumcaval) ureter is an uncommon congenital anomaly involving the venous system which results in the right proximal ureter coursing behind and at times becoming obstructed by the inferior vena cava (IVC). The basic abnormality developmentally is the abnormal persistence of the right subcardinal vein (instead of the right supracardinal vein) forming the main portion of the IVC ventral to the ureter. Ureter then winds behind medial to the IVC instead of staying lateral to it. Hence the term retrocaval ureter is anatomically descriptive but misleading in regard to development. The first case of retrocaval ureter repair was published in 1949 by Anderson and Hynes (1). Herein we report 5 cases of retrocaval ureter treated successfully by surgical repair.

\section{Patients and methods}

We carried out a retrospective study of patients with retrocaval ureter seen in a single urology unit of a tertiary referral centre over a period of 8 years since October 2001. The data were collected from the operation register and clinic files. The diagnosis was suspected with the finding of significant dilatation of the right pelvicalyceal system and proximal ureter to the level of the transverse process of L3 vertebra with the classical S shaped or "fish-hook" deformity at the point of obstruction on intravenous urography (Figure 1). This was confirmed by right retrograde ureteropyelography (Figure 2). All patients were symptomatic and underwent open surgical correction. The dilated renal pelvis (upper ureter) was transected, following which the ureter was transposed to its normal anatomic position. Before the pyelopyelostomy (ureteroureterostomy) retrocaval segment of ureter was examined for its healthiness. The indwelling ureteral stent which was inserted to splint the anastomosis was removed 6 weeks after the surgery. ${ }^{99 m}$ Tc DTPA renogram was performed 3 or 4 months after the surgery to confirm the relief of ureteric obstruction. 


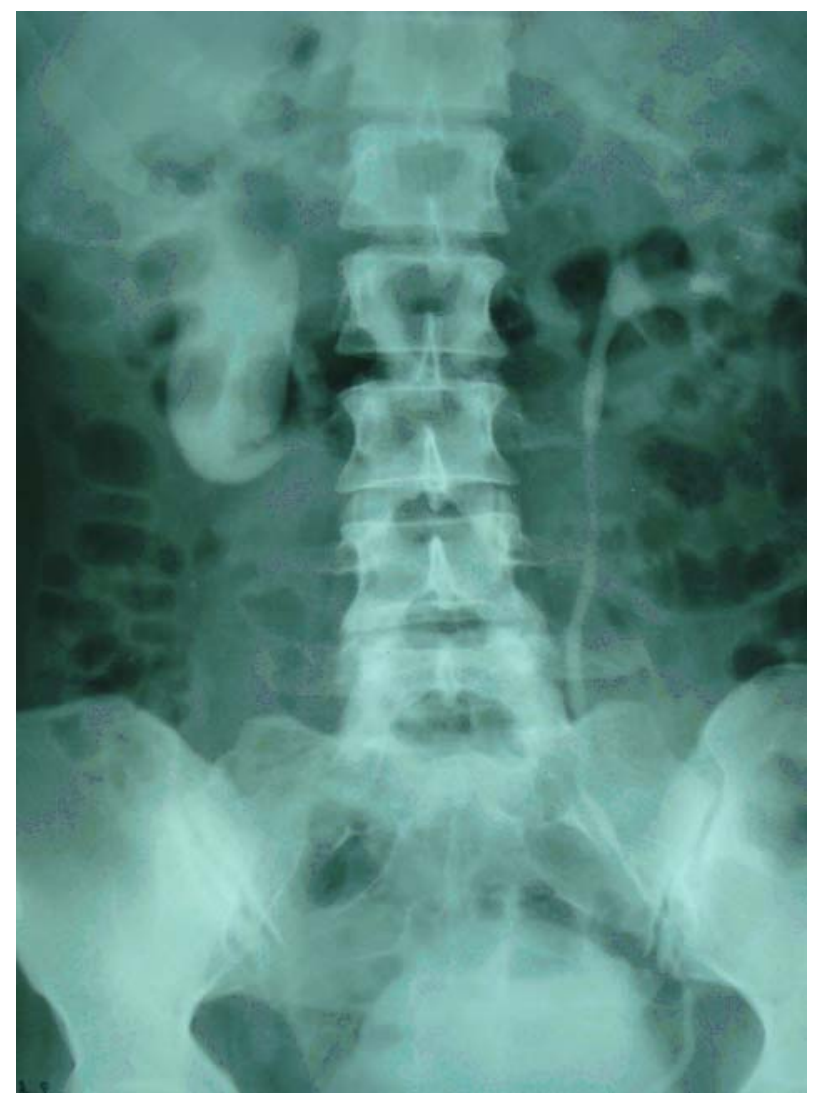

Figure 1. Intravenous urogram showing the classical $S$ shaped or "fish-hook" deformity in retrocaval ureter.

\section{Results (Table 1)}

There were 5 patients with retrocaval ureter. The mean age of the patients was 33 years (range 27-39 years). Out of 5 patients 4 were males. All 5 patients presented with right flank pain and 3 of them had haematuria and

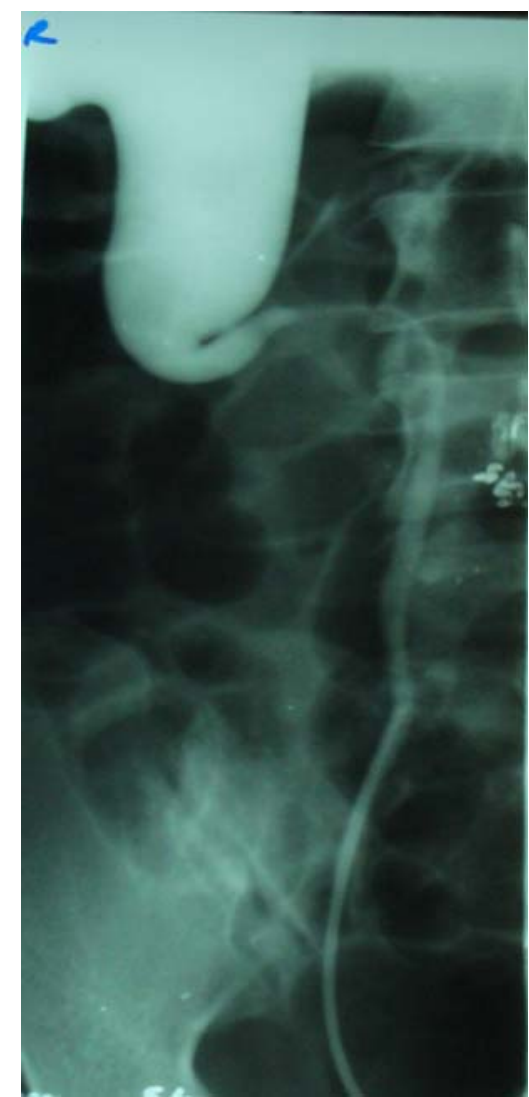

Figure 2. Right retrograde ureteropyelogram showing retrocaval ureter.

a small mobile renal stone. All patients had type 1 rightsided retrocaval ureter. Associated anomalies were seen in none of the patients. All patients were asymptomatic after the surgical correction. Post operative ${ }^{99 \mathrm{~m}}$ Tc DTPA renogram was normal in all patients.

Table 1. Clinical, radiological and operative details of patients with retrocaval ureter

\begin{tabular}{|c|c|c|c|c|c|c|}
\hline Patient No & Age & Sex & Clinical Presentation & Diagnosis & Operation & Outcome \\
\hline 1 & 33 & Female & $\begin{array}{l}\text { Right flank pain } \\
\text { - } 2 \text { months }\end{array}$ & $\begin{array}{l}\text { IVU, } \\
\text { RUP }\end{array}$ & $\begin{array}{l}\text { Pyelopyelostomy } \\
\text { (ureteroureterostomy) }\end{array}$ & $\begin{array}{l}\text { Asymptomatic, }{ }^{99 \mathrm{~m}} \mathrm{Tc} \text { DTPA } \\
\text { renogram - non obstructed }\end{array}$ \\
\hline 2 & 27 & Male & $\begin{array}{l}\text { Right flank pain and } \\
\text { haematuria }-2.5 \text { months }\end{array}$ & $\begin{array}{l}\text { IVU, } \\
\text { RUP }\end{array}$ & $\begin{array}{l}\text { Pyelopyelostomy } \\
\text { (ureteroureterostomy) }\end{array}$ & $\begin{array}{l}\text { Asymptomatic, }{ }^{99 \mathrm{~m}} \mathrm{Tc} \text { DTPA } \\
\text { renogram - non obstructed }\end{array}$ \\
\hline 3 & 32 & Male & $\begin{array}{l}\text { Right flank pain and } \\
\text { haematuria }-1.5 \text { months }\end{array}$ & $\begin{array}{l}\text { IVU, } \\
\text { RUP }\end{array}$ & $\begin{array}{l}\text { Pyelopyelostomy } \\
\text { (ureteroureterostomy) }\end{array}$ & $\begin{array}{l}\text { Asymptomatic, }{ }^{99 \mathrm{~m}} \mathrm{Tc} \text { DTPA } \\
\text { renogram - non obstructed }\end{array}$ \\
\hline 4 & 31 & Male & $\begin{array}{l}\text { Right flank pain and } \\
\text { haematuria - } 1.5 \text { months }\end{array}$ & $\begin{array}{l}\text { IVU, } \\
\text { RUP }\end{array}$ & $\begin{array}{l}\text { Pyelopyelostomy } \\
\text { (ureteroureterostomy) }\end{array}$ & $\begin{array}{l}\text { Asymptomatic, }{ }^{99 \mathrm{~m}} \mathrm{Tc} \text { DTPA } \\
\text { renogram - non obstructed }\end{array}$ \\
\hline 5 & 39 & Male & $\begin{array}{l}\text { Right flank pain } \\
\text { - } 1 \text { year }\end{array}$ & $\begin{array}{l}\text { IVU, } \\
\text { RUP }\end{array}$ & $\begin{array}{l}\text { Pyelopyelostomy } \\
\text { (ureteroureterostomy) }\end{array}$ & $\begin{array}{l}\text { Asymptomatic, }{ }^{99 \mathrm{~m}} \mathrm{Tc} \text { DTPA } \\
\text { renogram - non obstructed }\end{array}$ \\
\hline
\end{tabular}

IVU - intravenous urogram, RUP - retrograde ureteropyelogram 


\section{Discussion}

Retrocaval ureter is an uncommon congenital anomaly. Abnormal embryologic development of the inferior vena cava due to the failure of atrophy of the right subcardinal vein in the lumbar portion results in retrocaval ureter. The first recorded case of retrocaval ureter was seen on autopsy and was described by Hochstetter in 1893 (2). The incidence at autopsy is about 1 in 1500 (3). Retrocaval ureter is almost always right sided; however, in cases with situs inversus or duplication of the inferior vena cava, it may be seen on the left side $(4,5)$.

The incidence of retrocaval ureter is higher in men than in women 4:1 (6), and most patients do not present with symptoms until the third or fourth decade of life (7). The symptoms depend on the degree of ureteric obstruction or the presence of complications. Intermittent flank pain is often noted as the first complaint. Occasionally, recurrent urinary tract infection, haematuria, pyelonephritis or stone formation is noted (8).

Bateson and Atkinson classified retrocaval ureter into two clinical types: [1] the more common type I has hydronephrosis and typically obstructed demonstrating some degree of fishhook-shaped deformity of the ureter at the level of the obstruction, and [2] type 11 has a less degree of obstruction or none at all. Here the upper ureter is not kinked but passes behind the vena cava at a higher level, with the renal pelvis and upper ureter lying almost horizontal before encircling the vena cava in a smooth curve (9).

In our study all patients had right sided type 1 retrocaval ureter; the mean age of patient at presentation was 33 years; male to female ratio was $4: 1$; all patients had loin pain as presenting symptom.

Associated anomalies with retrocaval ureter are reported up to $21 \%$ and are mainly related to the cardiovascular and urogenital systems. The associated anomalies include horseshoe kidney, contralateral renal hypoplasia or ectopia, Turner's syndrome, Goldenhar syndrome, retroperitoneal fibrosis, polycystic disease of the kidneys, congenital lack of the vas deferens and hypospadias. None of these anomalies were documented in our patients.

Retrocaval ureter has been previously diagnosed by intravenous urography and retrograde pyelography, but nowadays, CT scan is the best modality for diagnosis (10). MRI can nicely demonstrate the course of a retrocaval ureter and may be more detailed when compared with CT or retrograde uretero-pyelogram (11). Nuclear diuretic renogram can categorize the anomaly as obstructed or nonobstructed. In our patients the diagnosis was made by both intravenous urography and retrograde ureteropyelography.

Procedural intervention is indicated in the presence of functionally significant obstruction leading to pain or other complications. The standard repair of retrocaval ureter is open surgical pyelopyelostomy or ureteroureterostomy. Pure laparoscopic repair of the retrocaval ureter has been performed both transperitoneally and retroperitoneally $(12,13)$. Pure robotic retrocaval ureter repair is feasible. Apart from the ergonomic and technical benefits that the robotic approach gives to the surgeon, there does not appear to be any other advantage over the laparoscopy (14). All of our patients were asymptomatic and obstruction free at 3 or 4 months after open surgical pyelopyelostomy (ureteroureterostomy).

\section{References}

1. Anderson JC, Hynes W. Retrocaval ureter: A case diagnosed pre-operatively and treated successfully by a plastic operation. Br J Urol 1949; 209-14.

2. Hochstetter F. Beitrage zur Entwicklungsgeschichte des Venensystems der Amniten: II. Reptilien (Lacerta, Tropidonotus). Morphol Jahrb (Leipzig) 1892-1893; 19: 428-501.

3. Heslin JE, Mamonas C. Retrocaval ureter: Report of four cases and review of literature. J Urol 1951; 65: 212

4. Wang LT, Lo HC, Yu DS, Sun GH, Wu CC, Fong CJ. Ureteral obstruction caused by a duplicated anomaly of inferior vena cava. Int J Urol 2005; 12 : 842-4.

5. Gramegna V, Madaro A, Pellegrini F, et al. A rare case of retrocaval ureter associated with persistent left venacava. Urol Int 2003; 70: 337-8.

6. Xiaodong Z, Shukun H, Jichuan Z, et al. Diagnosis and treatment of retrocaval ureter. Eur Urol 1990; 18: 207.

7. Kenawi MM, Williams DI. Circumcaval ureter: A report of four cases in children with a review of literature and a new classification. Br J Urol 1976; 48: 183.

8. Arana VA, Hodson JM, Kaiser TF. Retrocaval ureter. Am Fam Physician 1971; 4: 83.

9. Bateson EM, Atkinson D. Circumcaval ureter: A new classification. Clin Radiol 1969; 20: 173. 
10. Kellman GM, Alpern MB, Sandler MA, Craig BM. Computed tomography of vena caval anomalies with embryologic correlation. Radiographics 1988; 8: 533.

11. Uthappa MC, Anthony D, Allen C. Case report: Retrocaval ureter: MR appearances. Br J Radiol 2002; 75: 177-179.

12. Matsuda T, Yasumoto R, Tsujino T. Laparoscopic treatment of a retrocaval ureter. Eur Urol 1996; 29: $115-8$.

13. Ramalingam M, Selvarajan K. Laparoscopic transperitoneal repair of retrocaval ureter: Report of two cases. J Endourol 2003; 17: 85.

14. Hemal AK, Rao R, Sharma S, Clement RGE. Pure robotic retrocaval ureter repair. Int Braz J Urol 2008; 34: 734-8.

\section{Authors}

Balasubramaniam Sathesan, MBBS (Jaffna), MS (Col)*

A. P. I. Prabath, MBBS (Ruhuna), MS (Col)*

*Senior Registrar in Urology

S. A. S. Goonewardena, MS (Col), FRCS (Eng), DUrol (Lond)

Consultant Urological Surgeon

Department of Urology, National Hospital of Sri Lanka, Colombo, Sri Lanka. 